tional system include technical schools? How shall their distribution among the various vocations and
professions be symmetrically effected? To what extent and in what manner should the State sustain riculuin, and method of the schools already estabconstitute the great problems of the citizen, the educator, the legislator, and the statesman of our time. Such questions as these demand discussion and action,
imperatively and continuously. They are more pressation of adjacent provinces or choice of gold or silver iron or copper, for our coinage. Economical errors o the latter sort may isolate us from the rest of the world; but errors in the moral and intellectual, or the
technical, training of the people, may make home life

less satisfying.
The magnitude of the demand for technical instruction in the United States is greater than is usually demand-is far beyond the ordinary estimates of even the educator engaged in this special work. The writer has estimated that, were the United States, as tion of its people as do some of the provinces of France,
and of Germanyespecially, there would be established: of engineering and higher technique, 50 instructors
and 500 pupils each.

Fifty trade schools and colleges, of 20 instructors and
and 300 students each.

schools, or manual training schools, of 10 instructors and 200 pupils each.
That is to say: There should be in the United States That is to say: There should be in the United States
to-day, 1,000 university professors and instructors, and 10,000 students under their tuition, studying the highest branches of technical work; there should be 1,000
college professors and 15,000 pupils in trade schools. studying for superior positions in the arts; $; 20,000$
teachers engaged in trade and manual training schools, teachers engaged in trade and manual training schools,
instructing pupils, 400,000 in number, proposing to be instructing pupils, 400,000 in number, proposing to be-
come skilled workmen. We have in this country boys who should be in the latter class of schools. The cost of such education would be, per annum, about 50 cents per inhabitant additional to the present school tax, and in the shops of these schools less than $\$ 100$ per

'The actual number of schools of the highest class in versities nor colleges, but, usually, either schools restricted curricula, as engineering schools, or single eral and mainly liberal learning-is about fifty. The number of real trade schools prepared to give proper
training, scientific and practical, in any one trade, is rare, and a thoroughly representative trade school, like hundreds of those scattered all over Europe, is un known. We have. perhaps, a dozen good manual training schools in the larger cities; but we have no
system of carefully organized, complete and well-sustained schools of either class, supported by nation, bs
State, by city, or by any form of public or private
permanent systematic effort.

"Such is the intimidating comparison, also, of the condition of our country and the more enterprising lave bad two generations the start of us, and only the the more extraordinary general intelligence and enterprise of its citizens can possibly prevent this disadvanin the course of time when the inevitable competition of the world shall affect us."* On the other hand, every State is doing more and
seeing more each year of the duty before it, and its importance, and the State universities and the independent colleges and schools are feeling their way con-
stantly. though slowly, toward the solution of this titted to benefit by the opportunities which may be
thus offered and to secure, in the interim, those kinds of training and those forms of knowledge which are system, and to compete with other nations at this dis--
advantage. The freedorn of our institutions has enadvantage. The freedorn of our institutions has en-
gendered freedom of will and of intellectual action and the free action of a thousand ninds, untrammel ed, though untrained, preserves us against dangerous
rivalry from the better schooled but intellectually enslaved masses of the world outside. What will be the
final outcome of the changes which are now slowly final outeome of the changes which are now slowly
evolving an educational system in this country, and evolving an educational system in this country, and
at the same time giving freedom and stimulus to Eu-
ropean peoples, no one can predict. It can only be hoped that we may, in good time, have our own an' an ample and efficient, "complete and perfect,"system our people. cation of the nation, but we are making som
toward the production of what is needed.
The character of our technical

yet as unsettled and various as the independent and yet as unsettled and various as the independent an
far-separated points of origiu permit. The State uni-
versities usually offer a few farly well-defined course in engineering and architecture and in the science and art of agriculture, and a few of the independent col
leges stand beside them. The higher and lower literary colleges usually do but little in this field, and do pendent schools have as many standards of work as
they have foundations. Some demand a good high they have foundations. Some demand a good high
school preparation; others only a few selected prepar-
atory studies, and they, often, very elementary. Of the endowed schools some, as the Massachusetts Insti tute of Technology, are able to offer numerous courses
in science and in the constructive work of applied science; others, as the Renstructive work of applied but strong course. Some approximate offer a single university in their magnitude, extent and variety of work; the others, often denominating themselves en
gineering colleges, give a nondescript trade-schoo

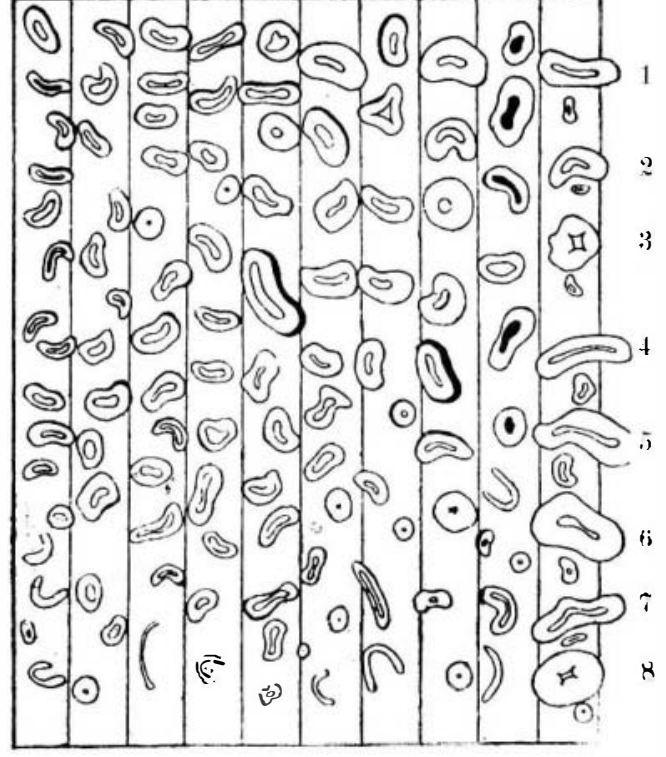

Scuit: Thousandus of an INCh

Tahiti. 2. Brown Egyptian. 3. Orleans. 4. Rough
Peruvian. 5. Maceio. 6. Scinde. 7. Lagos. 8.
China. 9. Red Peruvian. 10. Extremes in 1-8.

chester, who is now devoting his time to their preparation. The difficulties lying in the way of the pre when it is remembered that the diameter of a cotton
fiber may vary from to 10 an inch at the tip to sections noticed herein are only the $\frac{1}{200}$ of an inch in Of cotton fibers there is a goodly selection in trans-
then verse section, accompanied also by several stained
slides of the entire fiber, showing the endochrome and the full length of the staple. We have examined
them all under the $8 \mathrm{~mm}$. Zeiss apochromatic objective of $0.65 \mathrm{~N}$. A., and also by the $4 \mathrm{~mm}$. objective $(0.95$
$\mathrm{N}$. A.) of the same series, using the 12 and 18 oculars, and we can say with confidence that we have never
examined specimens of such perfect preparation. The wood cut will give an idea of Mr. Flatter's work.
The slides of Peruvian are exceedingly instru The slides of Peruvian are exceedingly instructiv is cut in slices of " 1510 to $\frac{10}{200}$ of an inch in the sections showing all positions from apex to base, and containing specimens of "dead" or "unripe"
cotton; the bete noire of many a dyer. The "red"
Peruvian is cut somewhat thicker, and shows the deposit of endochrome in the inner tube. The Egyptian brown is another slide of this character, not n many sections the cellulose substance is also colored. "Gallini" also exhibits a light yellow enof cellulose within the investing membrane are those sights under the Zeiss $2 \mathrm{~mm}$. apochromatic of $1: 30$
N.A., and the 12 compensating ocular. To those who under common objectives we advise a careful perusal The slide of China cotton is a good specimen of well matured fiber, while the "Nankin shows a yellow
endochrome more intensely than even Egyptian brown. Among the East India cottons we have "Rangoon," "Oogos," while Brazilian is represented by "Ceara" and "Maceio," all these sections being cut There is a slide of "extra fine" Sea Island cotton, and also of "Tahiti," the latter being better than the point of view, showing as it does every point from "unripe" to fully matured, and a slight deposit of endochrome likewise. A section of 60's yarn and a section of bleached cotton stained with catechu con-
cludes this series. In the latter the whole cellulose cludes this series. In the latter the whole cellulose
contents are stained brown, and the investing memontents are stained brown,

Among other textile fihers the transverse section of the stenof Linum usitatissimum show sthe flax fibers in situ, while another slide exhibits the fibers when isolated. The stem of Cannabis sativa also shows
the fibers in situ, the transverse section of the hemp fibers themselves making another slide in the series. The fibers of the Corchorus capularis (jute) have been very neatly sectioned, and exhibit great dissimi-
larity to the two former fibers. The Brhmeria nivea or china grass, known also as "Tchou-ma," or slides, the entire fiber, a section of the same showing
it to be quite distinct from the flax, hemp or jute, it to be quite distinct from the flax, hemp or jute, and a longitudinal and transverse section of the stem
of the plant from which the fibers are procured. will give the reader an idea of the contents of this useful series. Mr. Flatters prepares lantern slides showing the details of the foregoing textile fibers, extremely valuable to all those engaged in technical instruction; the slides are prepared on a micrometric background,
and every detail has been so thoroughly considered in their preparation that we have felt it our duty to cal Trade Journal.

THE FIRST PHOTO MECHANICAL REPRODUCTION. By Julius F. Sachse.

Professor S. R. Koehler, curator of the Section of Graphic Arts in the Smithsonian Institution, anc questions our claim made in the American Journal ton, of Philadelphia, is due the honor of making the first practical plioto-mechanical reproduction used on a printing press. He even goes so far as to deny that
the Saxton specimen was a photo-mechanical reproduction in the accepted meaning of the term.

that "a photo-mechanical reproduction" is one for which the printing form has been made principally by the action of light, aided by etching, washing out, etc.,
without the intervention of the human hand except without the intervention of the human hand except
for corrections, elimination of defects, etc. done by mechanical means-i.e., on a press. This second requisite the Saxon vignette as a matter of a roller press.
Then Professor Koehler goes on to state that the first requisite is not met. For even, he continues, "if the view of the mint should have been daguerreotyped which is impossible, as the character of the view shows,
it still would have had to be engraved or sunk by the human hand" authority as above quoted, the writer still adheres to
the original claim as made in the American Journal. repeated before the Franklin Institute. The facts of the case simply stated are: In 1841, Joseph Saxton, a type of the Philadelphia mint for the purpose of obtaining a printing plate for the title page of a book
about to be issued. The daguerreotype was then about to be issued. The daguerreotype was then
placed in the battery, and an electrotype made of the original. This was separated from the daguerreotype. Gobrecht, the en-
graver, then took this intaglio and strengthened cergraver, then took this intaglio and strengthened cerken from this corrected intaglio and backed, from which the plate was ruled, giving, as Eckfeld says in
the text quoted, "a faithful and beautiful transcript haps much less handwork done on the first electrotype
than there is on many a Goupil photogravure of the present day, Further, this result was a practical plate, from which large edition was printed. It may be of interest to type portrait made from a daguerreotype may still be seen in the Gutekunst rooms, 712 Arch Street, Phila-
delphia. It is dated 1853, and was made by Mr. F. Gutekunst personally. that in all fairness the objections to the first requisit are disposed of. owever, the question as the states: "I it is 'the first photo-mechanical production' made in the year 1841. Neciphore Niepce began his experiments looking to the making of printing plates, $i . e_{\text {, }}$
plates printable in a press, in the year 1813 . There is still in existence a plate made by him from an engrav-
ing in the year 1824. This plate is preserved in the Museum at Chalon-sur-Marne, and an impression from the United States National Museum, Washington, D. the It is but fair to state that there is a slight doubt
as to the absolute correctness of this date, as Niepcede Victor says that his uncle obtained plates made after difference, however, is only three years." 
facts of the case are as follows: The impression alluded to is a portrait of Cardinal Georges d'Amboise, print was made is of block tin, and it is alleged was
obtained as follows: The metal is said to have been coated with a solution of asphalt and Dippel's oil (obtained by the dry distillation of bones). Upon the and after being printed in the sun it was fixed with a solvent, and then lightly etched with acetic acid sian engraver, to have the lines engraved and deepened, so as to give it a printing character.

The strangest feature about this story is that no on knew anything about either plate or print until it disclosure after a lapse of forty years, by Isidore que, dated March 10, $186^{\circ}$, who was then compiling his "La Verite surl'Invention de la Photographie" (Paris, 1867). Vide also. Dr. J, M. Eder, Handbuch, Halle a. S., 1891, pp. 109-114.

There is certainly no comparison to be drawn between this alleged crude attempt of Nicephore Niepce which, even if true, was of no commercial value, and the practical result obtained by Joseph Saxton, th of photography.-American Journal of Photography.

\section{VARNISHES AND VARNISHING.}

DR. VALENTA has dealt rather exhaustively with this subject, and he points out that the heating of the plate-so much objected to by amateurs-is by $n$ tory, if made and used to the best advantage. He speaks first of those cold alcoholic varnishes which are mostly solutions of gum sandarac in alcohol; but
as such a solution of sandarac in alcohol will give only as such a solution of sandarac in alcohol will give only a matt surface, these varnishes contain certain other
additions. Such additions are oil of lavender, oil of citron, etc.. and he gives in the following a formula citron, etc.. and he gives in the following a formula thoroughly tested :

$$
\begin{aligned}
& \text { Gum sandarac } \\
& \text { Alcohol } \\
& 18 \text { grammes }
\end{aligned}
$$

This varnish dries rather slowly, but gives a solid and only slightly sticky film, excellently suited for re which, even after hours of drying, will leave impressions if touched by the hand.

He then speaks of cold varnishes containing ammonia. Such a varnish is, for instance, the "crysta varnish" of Durkes. These varnishes are easily re cognized, even if no great excess of ammonia should be present; or if they are perfumed, as when heated, discernible by its odor and the alkaline reaction of the gas. These varnishes are an imitation of ammonia shellac varnishes used in collotype, and contain mostly shellac as the resin. This gum, dissolved in alcohol, does not give a clear film if the plate has not ween heated before, while an addition of ammonia cold plates. The ammonia is added mostly after the solution of the shellac in alcohol has taken place For the production of such varnishes a solution of ammonia pas in alcohol is, according to his experiments, the most suitable; in this the shellac will only well in the cold, but will dissolve easily to a clear, tion of such a varnish

Alcohol saturated with ammonia. 100 c.c

Shellac............... 8 grammes.

If the varnish is desired thicker, the quantity of the shellac can be increased up to fourteen per cent. Th solving shellac in alcohol and subsequent mixing with ammonia in aqueous solution.

Cold varnishes containing ether and acetone contain ither sandarac or some other hard gum, and copal or amber, in which latter case they excel in quickness of drying and great hardness, while the cold varnishes of this kind containing sandarac are generally somewhat following he gives a formula for the production of a 30 grammes angola copal and 5 grammes amber are powdered and mixed with

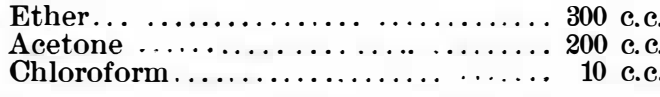

These gums are brought to a partial solution by prolonged standing in the solution, and shaking from time digested from one to two hours with the dissolving medium. A part of the gum will dissolve quickly

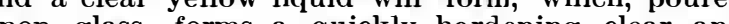
upon glass. forms a quickly hardening, clear, and Benzole cold varnishes generally contain sandarac or gum dammar. Varnishes prepared with the latter gum are always softer than the former. As these gums dissolve only with difficulty in benzole, artificial means must be employed, by treating first of benzole. If proceeded with in this my quantity varnishes are obtained, which furnish a solid, clear A good formula of this kind is the following : Benzole 90 c.c.

Gum dammar.................... 8 grammes.

This gum can also be applied to papers, and for this purpose a corresponding dilution is necessary. In such utta-percha. Collodion Cold Varnish.-Varnishes of this kind
sold as crystalline, brassolline, or Zapon varnish mostly sold as crystalline, brassolline, or Zapon varnish mostly
contain amyl acetate. They consist of pyroxyline
which has been dissolved in amyl acetate and acetone with or without the addition of benzole, and sometimes camphor.
The quantity of amyl acetate in these varnishe
makes the use of the same under certain circum tances very disagreeable; but they form very solid

Such a varnish can easily be produced by pouring
Such 1,000 c.c. acetone upon 150 grammes pyroxyline, and , 000 c.c. benzole. - Photographic Work.

\section{A FEW CURIOSITIES.}

JUST now, when the Columbian Exposition has atracted universal attention to so many strange people rom out-of-the-way places, we feel sure that our read-

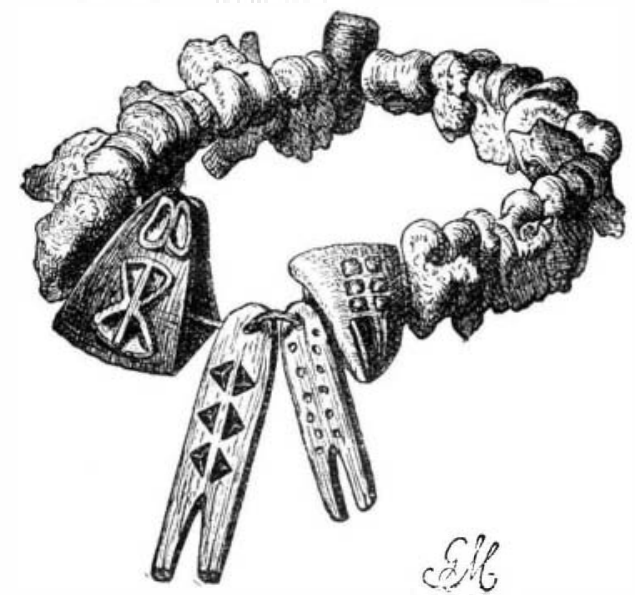

CAFFRE DOCTOR'S AMULET.

from Meyer's Konversationslexikon, for which we are Zeitung. The first of these engravings represents an amulet of the kind used by the charm doctors of the Caffres. a native race of Southern Africa. These people have no onception of a Supreme Being, but believe implicitly ing by the latter. Their charm doctors, rain maker and prophets exercise great power over them. Other South African nations are represented by the

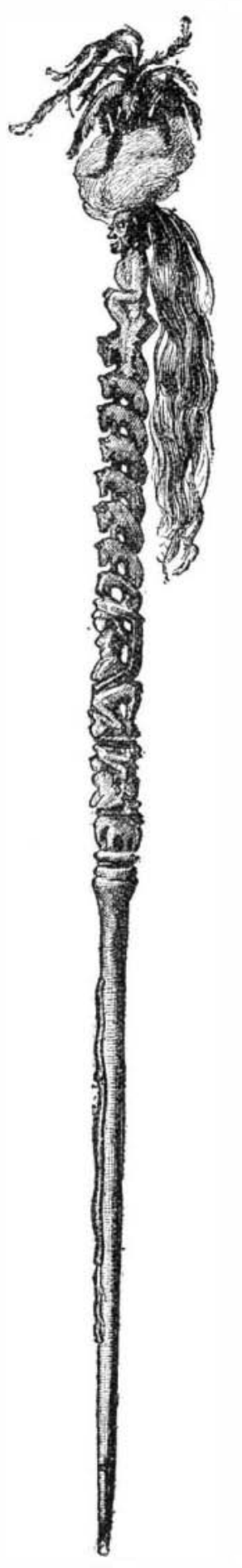

BATTA DANCING STAFF. intellectual development, but these have not only a very the inner bark of a kind of palm cut into long strips and folded in squares, part of the wood being left a the ends to form the covers. But apparently this mental progress has not carried refinement or delicacy f feeling with it.

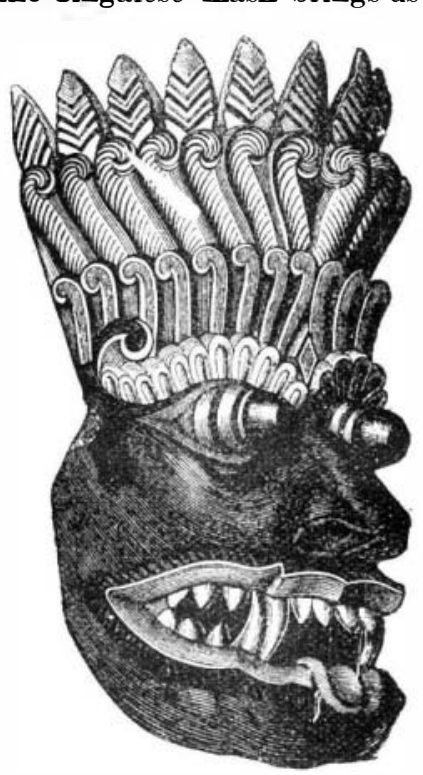

CINGALESE MASK rammar. They have a literature that includes work on religion, botany, history and lexicography. These and the native races in China and Japan, are worship-
ers of Buddha. A bronze image of this god is shown in one of our engravings. As every one knows, all of these nations have attained a high degree of civilizaworld for their fine and artistic workmanship. This is

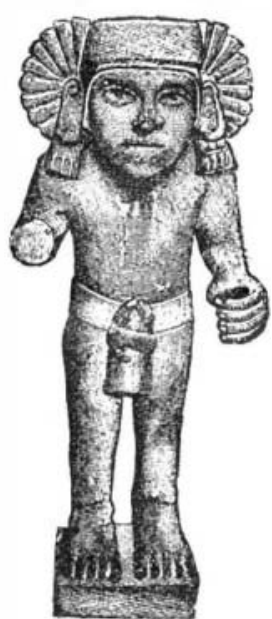

MEXICAN STONE FIGURE

Indian suit of armor. But some of the less civilized nations also possess artistic skill, as we may see by the cut of the Bashkir decoration, that constitutes a por-
tion of the costume worn by the people of this semibarbarous race that inhabits the territory lying beThe the Caspian Sea and the boundary of siberia. giving us a realizing sense of the fact that it, too, has

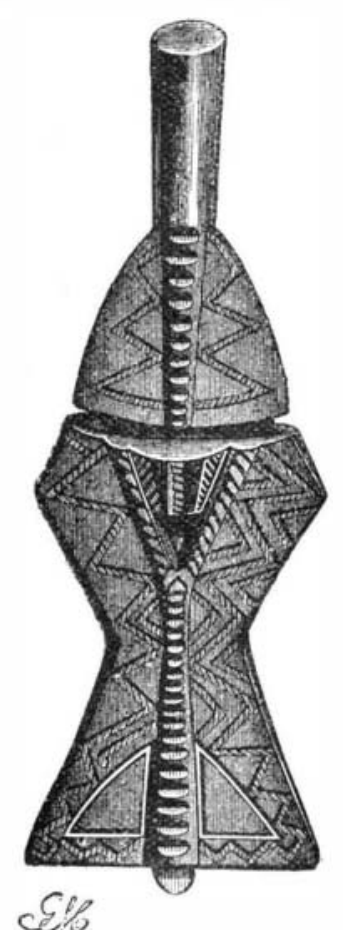

MARUTSE DAGGER write from left to right and their books are formed o

people possessed of a rich language with a regular tion, their ind ustrial products being noted all over the

cuts of the Marutse dagger-which is more elaborately cuts of the Marutse dagger-which is more elaborately $\begin{aligned} & \text { its antiquities, although generally called the "New } \\ & \text { decorated than the amulet-and of the Herero woman's } \\ & \text { headdress. }\end{aligned}$ World." One is a stone figure found in Mexico,
and the other the ancient pyramid of Xochicalco. Another picture shows a dancing staff used by the and the other the ancient pyramid of Xochicalco. atra. Cannibals are race of cannibals living in Sum- mid differ considerably from those of other Mexican 